\title{
Study of Solar Energy Potential using CMP6 Pyranometer at Nepalgunj, Nepal
}

\author{
Bed Raj KC ${ }^{1} \&$ Shekhar Gurung ${ }^{2}$ \\ ${ }^{1}$ Mahendra Multiple Campus, Tribhuvan University, Nepalganj, NEPAL \\ ${ }^{2}$ Central Department of Physics, Tribhuvan University, Kathmandu, NEPAL
}

Corresponding Email: bedrajkc@yahoo.com

\begin{abstract}
:
The global solar radiation (GSR) is measured at the horizontal surface since 2011 using calibrated CMP6 Pyranometer at Nepalgunj which is located at an altitude 150m above sea level. This paper explains the daily, monthly and seasonal variation of global solar radiation and also compares temperature withglobal solar radiation. The average temperature in Nepalgunj varies between $44^{\circ} \mathrm{C}$ (it is hottest from May through July) and $30^{\circ} \mathrm{C}$, although during winter (November-January) it can reach $4^{\circ} \mathrm{C}$. The annual average daily global solar radiation is about $12.9 \mathrm{MJ} / \mathrm{m} 2 /$ day which is sufficient to promote active and passive solar energy technology in Nepalgunj and other similar geographical locations.
\end{abstract}

Keywords: solar radiation, variation factors, solar photovoltaic.

\section{Introduction}

Nepal is a land-locked mountainous country with a large area of beautiful landscape situated between $26^{\circ} 22^{\prime}$ to $30^{\circ} 27^{\prime}$ North latitude and $80^{\circ} 40^{\prime}$ to $80^{\circ} 12^{\prime}$ East longitude within a span of 200 $\mathrm{km}$ from south to north and about $800 \mathrm{~km}$ from east to west (WECS, 2010).It shares borders with India on three sides and China on one side. Within this small and beautiful setting it possesses diversity in biosphere and variation of climate. It does not have its own coal and petroleum resources so far and has no access to the ocean. Geopolitical events are driving prices of fossil fuels steadily up. The short-term risks to political stability and economic activity posed by the world's dependence on fossil fuels are again as manifest as its long-term threats to environmental sustainability. To break this dependency, all the countries in the world need a clean energy revolution. Such a revolution would enhance global energy security, promote longterm economic growth and tackle environmental challenges such as anthropogenic climate change (IEA, 2011).

Nepal is a developing country, where a large fraction of the population still does not have access to modern day energy services such as electricity. This is due to limited fossil fuel resources and poor economy. Supply and consumption of energy is still in a traditional state in Nepal. It is fully dependent on traditional energy sources such as biomass. For commercial Purpose, the country is reliant on imported fossil fuels like petrol, diesel, kerosene and LPG for running vehicles, stationary engines, boilers, cooking, lighting etc. Such heavy dependence on biomass resources 
for energy has accelerated the depletion of natural resources and contributed to the degradation of natural environment. The country spends about 40 percent of its foreign currency reserve for the import of petroleum products. Available literature tells that consumption of petroleum products in Nepal is increasing at the rate of about 10\% per year (Source: NOC, 2011). This gap between supply and demand in power sector forces Nepal Electricity Authority to enforce power outage for 4 hours to 16 hours per day in spring and dry season respectively (K.N.paudel, 2010). Whereas, the country's vast renewable resources such as hydropower energy, wind energy and solar energy remain virtually unexploited. Being rich in natural resources, Nepal possess high potential of development of energy generation station. Nepal is located in the area with one of the highest solar energy potential in the world. Solar energy is very suitable form of energy for the country like Nepal. It is the best option for the generation of energy. This vast potential can be used to produce electricity. The study of solar radiation should incorporate solar radiation and local weather condition. The total solar radiation potential will be the key parameter for designing and predicting the performance of solar energy equipment and solar energy potential (Sukhera, 1987). The global solar radiation is affected by clouds, water vapor, aerosols, ozone, and other gases. The cloud is the key affecting factor of solar radiation. Actually the water vapor concentration varies during the day and also varies seasonally. Thus high concentration of water vapor is found during moist season than during dry season. Not only the parameters mentioned above affect the amount of solar radiation reaching the earth surface, but also the incident angle of solar radiation. This angle varies with time, season and location. The geographical distribution of solar radiation over a region is normally different from other regions due to the position and atmospheric constituents of the local weather condition (Janjai.S., 2008). Cloud is primarily responsible for the fluctuating intensity of sunshine hours on the ground surface.

Applications other than electricity production, solar water heaters and solar cookers also have vast applications. Photovoltaic, thermal devices should be used to generate the solar energy. Efficiency of photovoltaic solar panels is measured by the ability of a panel to convert sunlight into usable energy for human consumption. All the solar energy convertors utilize the radiations received from the sun. It is important in order to choose the correct panels for photovoltaic system by knowing the efficiency of such panel.

\section{Material and Method}

The primary data of daily solar radiation on horizontal surface for Nepalgunj were collected from the archives of the Department of Hydrology and Meteorology, government of Nepal. Daily sunshine duration, temperature and relative humidity data for these sites were obtained from the same Department. The data obtained covered a period of years from 2013 years for Nepalgunj(latitude $28.05^{\circ} \mathrm{N}$, longitude $81.62^{\circ} \mathrm{E}$ and altitude $150 \mathrm{~m}$ ). The most widely used ORIGIN/Microsoft Office Excel software has been used for the data analysis. 
The figure CMP6 Pyranometer is shown. The CMP6 Pyranometer has the operating temperature from $-40^{\circ} \mathrm{C}$ to $80^{\circ} \mathrm{C}$. It has wide spectral range of instruments from $310 \mathrm{~nm}$ to $2800 \mathrm{~nm}$. The sensitivity of instrument and field of view are 5 to $15 \mu \mathrm{V} / \mathrm{W} / \mathrm{m}^{\wedge} 2$ and $180^{\circ}$ respectively. In this instrument, the measuring data is recorded by LOGBOX SD data logger within a minute resolution for 24 hours. Its special features are low noise, high resolution and low power consumption. It works in all weather conditions. It collects the data at real time for the needs of meteorology and slow signal analysis. We can insert the SD memory card for long term data storage. For the communication LOGBOX uses either RS232 or RS485 communication port (Zonen, 2008).

\section{Study Area}

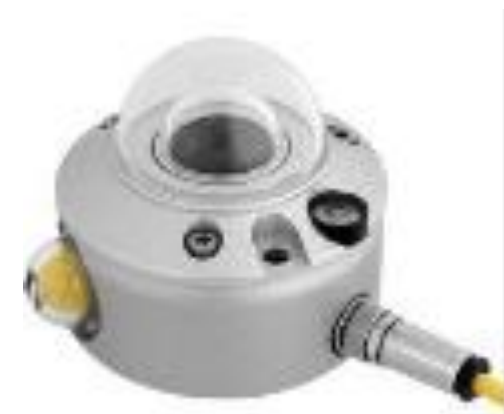

Nepalgunj is a Sub-Metropolitan municipality in Banke District, Nepal on the Terain plains near southern border with Utter Pradesh of India. Nepalgunj is the business and tourism hub of western Nepal. It is the gateway to Mount Kailash, Mansarobar, amazing beautiful Phoksundo lake, Rara lake and to some of the world's most beautiful scenic and adventurous trekking routes. Nepalgunj has a sub-tropical climate. Temperature highly affects the lifestyle of Nepalgunj. In summer season, temperature reaches upto $44^{\circ} \mathrm{C}$, while in the winter season, the temperature may drop to $4^{\circ} \mathrm{C}$. Nepalgunj also has religious significance. Bageshwari is a renowned temple for Hindus in the country as well as those from nearest bordering cities of India. The temple area also has another famous temple- the temple of lord Shiva with mustache, which is often referred to as Junge Mahadeva. Nepalgunj has diverse culture with people from different faiths living together in mixed communities.

\section{Result and discussion}

\section{Daily Variation of Global Solar Radiation in Nepalgunj}

The diurnal variation of global solar radiation varies due to inclination, solar zenith angle, and change in season and local weather conditions. Figure shows the daily variation of global solar radiation at the measurement site. The maximum solar radiation is found to be $29.7 \mathrm{MJ} / \mathrm{m} 2 /$ day on 30th of $e$. The team of IOE pulchok performed a study of Solar radiation in Pokhara valley in 2009. According to report of this team, the maximum solar radiation is found to be $28.86 \mathrm{MJ} / \mathrm{m} 2 /$ day on 4 th of June. 
ISSN: 2362-1303 (Paper) | elSSN: 2362-1311(Online)

Figure : Daily Variation of Global Solar Radiation in 2013

\section{Monthly Variation of Global Solar Radiation}

Figure shows the trend of measured and extraterrestrial global solar radiation is very much similar. However maximum solar radiation $24.21 \mathrm{MJ} / \mathrm{m}^{2} /$ day is found in the month of June. Statistical analysis indicates that the measured data are relevant as well as sufficient to explore the solar energy even in December when GSR is $13.32 \mathrm{MJ} / \mathrm{m} 2 /$ day. According to report of IOE team, the surface gets the maximum solar radiation $23.21 \mathrm{MJ} / \mathrm{m} 2 /$ day in the month of June and minimum solar radiation, which is $12.04 \mathrm{MJ} / \mathrm{m} 2 /$ day in the month of December. 


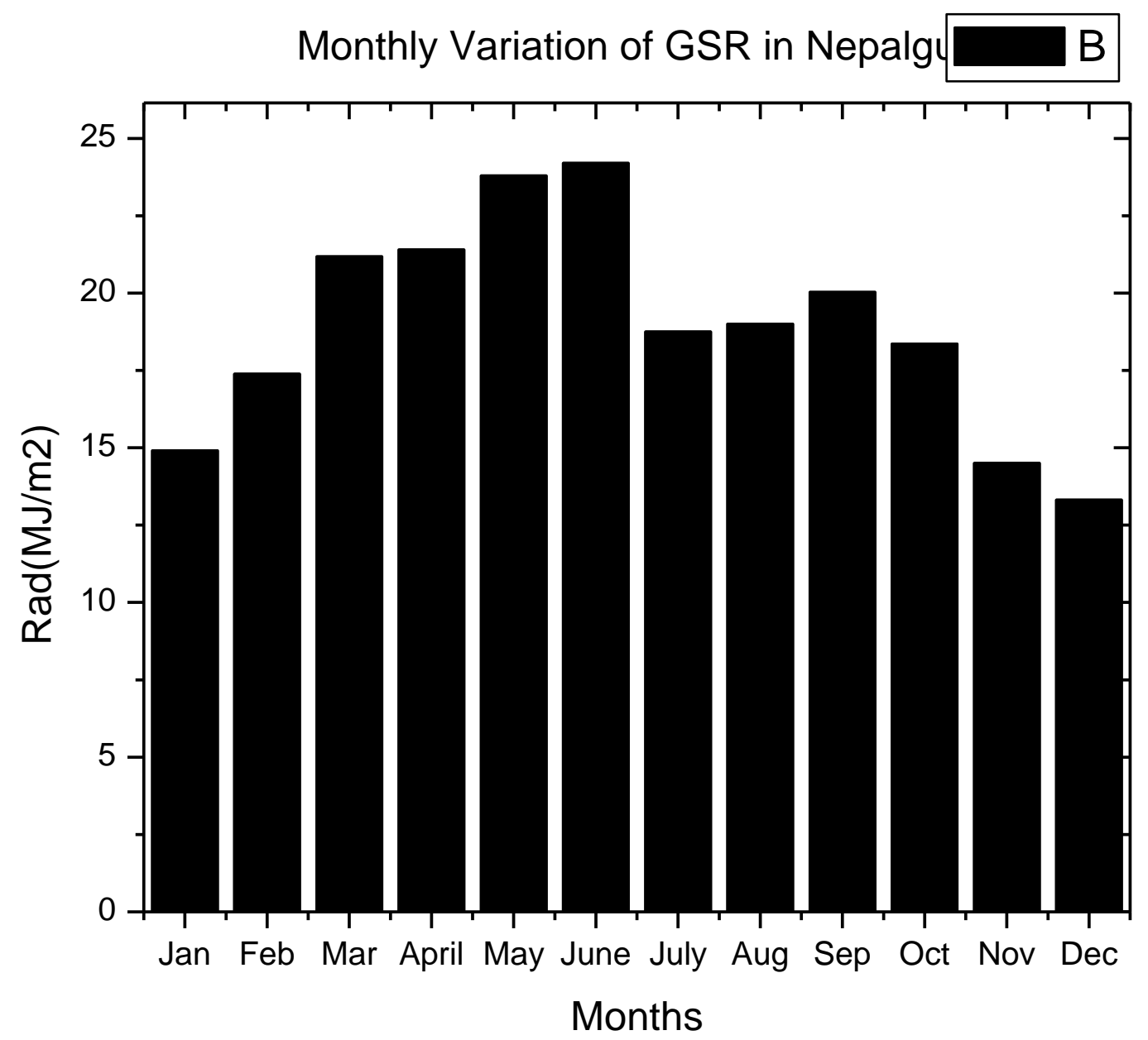

\section{Seasonal Variation of Global Solar Radiation}

Figure shows that the global solar radiation significantly fluctuates from season to season. The Nepalgunj region is part of the Terai area of Nepal. The measured solar energy for winter, spring, summer and autumn are 13.02, 19.31, 17.86 and $14.68 \mathrm{MJ} / \mathrm{m} 2 /$ day respectively. The maximum clear sky days are found in spring and minimum in winter. According to study of IOE team, the measured solar energy in Pokhara valley for winter, spring, summer and autumn are $14.01,19.90,18.95$ and $16.14 \mathrm{MJ} / \mathrm{m} 2 /$ day respectively. 


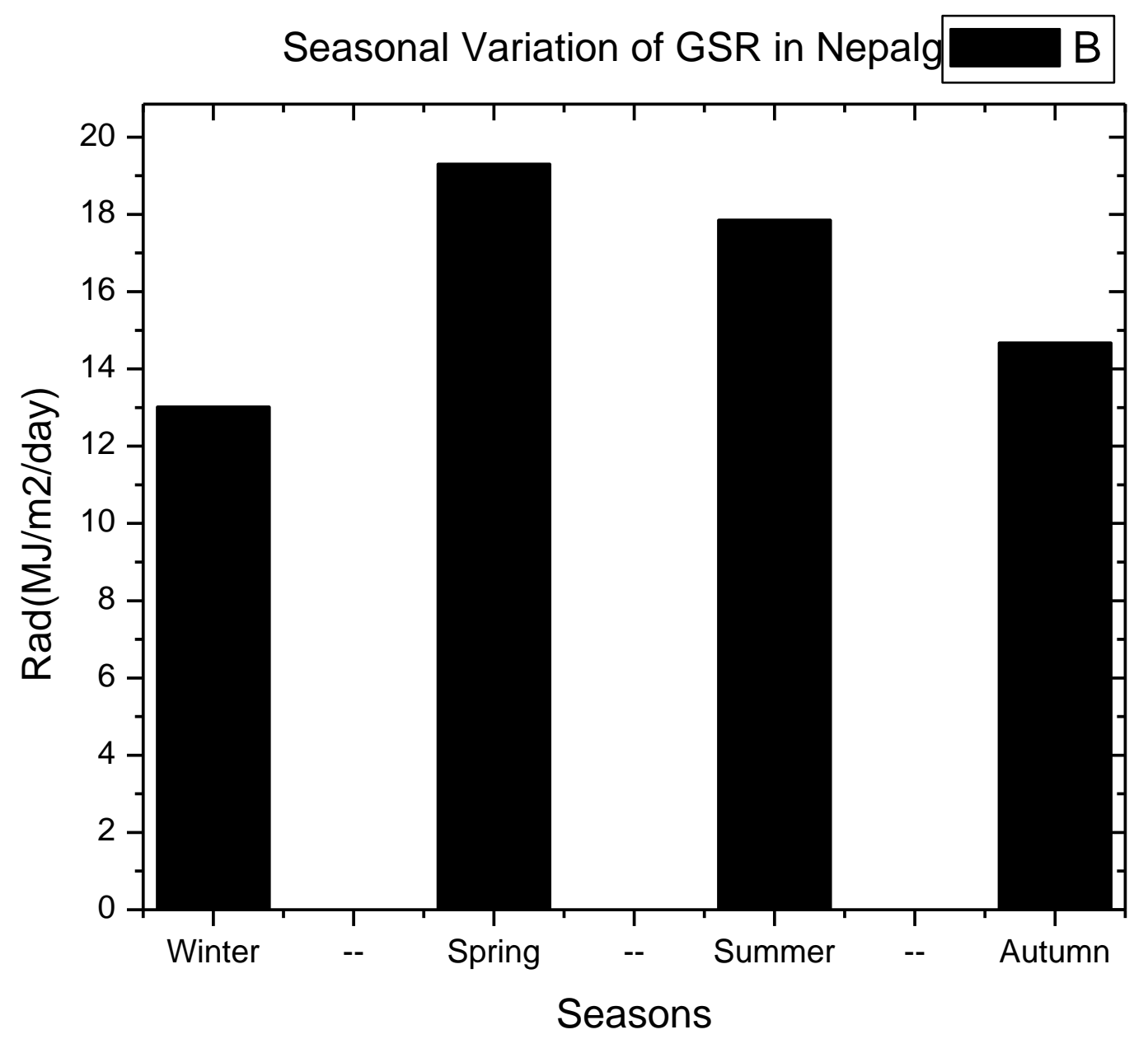

The team of IOE pulchok published its research on Solar radiation in Pokhara valley in 2009, which is similar to Solar radiation found in Nepalgunj in 2013.Hence the altitude as well as local weather condition also plays the vital role in determining the variation of global solar radiation in any part of Nepal(K.N.Poudyal, 2009).

\section{Conclusion}

It is found that the average global solar radiation is $12.9 \mathrm{MJ} / \mathrm{m} 2 /$ day in Nepalgunj, the report showed that such amount of energy is sufficient to promote grid connected solar photovoltaic (PV) for power generating plants in Nepalgunj. The global solar radiation varies from month to month and season to season depending on temperature and precipitation. The maximum and the minimum global solar radiation $19.31 \mathrm{MJ} / \mathrm{m} 2$ and $13.02 \mathrm{MJ} / \mathrm{m} 2$ are found in spring and winter season in Nepalgunj. However low global solar radiation is measured in summer due to the 
ISSN: 2362-1303 (Paper) | elSSN: 2362-1311(Online)

cloud and rainfall at Nepalgunj. Hence the topography as well as local weather condition also plays a vital role for the estimation of global solar radiation in any part of the world including Nepal. This study recommends that Nepalgunj and places having similar altitude/geographical/meteorological parameters are suitable for solar farming activities in Nepal. 
ISSN: 2362-1303 (Paper) | elSSN: 2362-1311(Online)

JOURNAL OF ADVANCED ACADEMIC RESEARCH (JAAR)

Jan 2016

\section{References}

Chibani, M. a. (2000). A Simple Method for Computing Global Solar Radiation. Rev. Energy.Chemss, 111-115.

Janjai.S. (2008). Assessment of Solar Energy Potentials for Combodia.

K.N.paudel, B. a. (2010). Estimation of Global Solar Radiation. Energy and power Engineering.

K.N.Poudyal, B. K. (2009). Estimation of Global Solar Radiation using Pyranometer and NILUUV IrradianceMeter at pokhara valley in Nepal. Journal of Institute of Engineering, pp 69-78.

Sukhera, M. a. (1987). Solar Radiation Maps for Pakistan. Pakistan Solar and wind Technology, 4(2),229-238.

Tsering, L. (1991). Role of Solar and wind wnergy in Nepal. Kathmandu: Integral Centre for Integrated Mountain Development.

UNFCO. (2012). District profile Jumla. Nepalgunj: United Nations Field Coordination,M.W.R.

WECS. (2010). Energy Sector synopsis Report. Kathmandu: Government of Nepal.

WECS. (2010). Energy sector Synopsis Report. Nepal. Kathmandu: Energy Sector Synopsis Report, Nepal.

WECS. (2010). water and Energy Commission Secreterial. Nepal: Energy sector Synopsis Report .

Zonen, K. a. (2008). 